\title{
BEM DE FAMÍLIA INTERNACIONAL (NECESSIDADE DE UNIFICAÇÃO)
}

INTERNATIONAL HOMESTEAD (NECESSITY OF UNIFICATION)

Álvaro Villaça Azevedo ${ }^{1}$

Resumo:

O bem de família nos EUA, a expansão desse bem a outros países e a sua possibilidade de unificação legislativa internacional são temas abordados pelo Autor civilista, que termina a matéria com proposta de lei sobre o bem de família internacional ao modelo jurídico brasileiro.

Palavras-chave: Bem de família. Novo conceito. Exceção de impenhorabilidade.

\begin{abstract}
:
The homestead in the US, the expansion of this concept to other countries and its possibility of international legislative unification are discussed topics of this paper, that ends with the proposal of a legal standard about the international homestead to the brazilian juridical system.
\end{abstract}

Keywords: Homestead. New concept. Exception of unpledgeness.

\section{Minha antiga proposta doutrinária ${ }^{2}$}

Ao defender minha tese de doutoramento, na Faculdade de Direito da Universidade de São Paulo, com a monografia sobre Bem de Família, em 18 de outubro de 1972, tinha em mente a completa reestruturação desse instituto jurídico, oferecendo, então, um esboço de anteprojeto.

Naquela oportunidade, enfrentei o deficiente tratamento do bem de família, pelo Código Civil brasileiro, de 1916, que foi corrigido, em parte, pelo Projeto de reforma desse mesmo Código, n. 634, de 1975, n. 634-B, depois de aprovado na Câmara dos Deputados, em 1984, ingressando no Senado da República, em seguida, sob o n. 118, tendo obtido redação final em 1997; tramitando, de retorno, na Câmara dos Deputados. Esse Projeto, contudo, não operou a sempre esperada, ampla e profícua, proteção da família brasileira; o que se manteve no Código Civil de 2002.

1 Doutor em Direito, Professor Titular de Direito Civil, Regente de Pós-Graduação e ex-Diretor da Faculdade de Direito da Universidade de São Paulo; Professor Titular de Direito Romano, de Direito Civil e ex-Diretor da Faculdade de Direito da Universidade Mackenzie, em São Paulo; Professor Titular de Direito Romano e Diretor da Faculdade de Direito da Fundação Armando Álvares Penteado, em São Paulo; Advogado e exConselheiro Federal e Estadual da Ordem dos Advogados do Brasil, Parecerista e Consultor Jurídico.

2 AZEVEDO, Álvaro Villaça. Bem de família, com comentários à Lei n. 8.009/90. 4. ed. rev. e ampl. São Paulo: Revista dos Tribunais, 1999. 254 p. A tese foi defendida em 1972 e a 1. ed. é de 1974. 
Demonstrei em meu citado livro, ao cogitar das espécies de bem de família que devem existir, que o modelo texano, escolhido pelo Código Civil brasileiro e pelos demais países, que o adotaram, já nasceu velho, pois procurou defender a família proprietária de bem imóvel, que existe em pequeno número, e com excesso de formalismos, e a inalienabilidade do imóvel. Mesmo no Texas, viveu-se, lá, exemplo peculiaríssimo, jamais experimentado no Brasil e nos aludidos países.

Como, ali, evidencio, nunca fui contrário a essa espécie de bem de família, que chamo de voluntário imóvel, todavia, ante sua insuficiência, propugnei pelas espécies de bem de família voluntário móvel (já cogitado, também, ainda que de modo incompleto, no aludido Projeto de novo Código Civil brasileiro) e do bem de família involuntário ou legal, criado por norma de ordem pública, com a proteção patrimonial, assim, de todas as famílias.

A Lei n. 8009, de 29 de março de 1990, dispondo sobre a impenhorabilidade do imóvel residencial e de bens móveis, em algumas circunstâncias, acabou por acolher, em parte, minha proposta doutrinária de criação de um bem de família legal, por imposição do próprio Estado.

Embora incompleta, como disse, essa Lei n. 8009/90 surgiu em boa hora, em que a Nação brasileira atravessava séria crise, principalmente, de ordem econômica.

\section{O bem de família nos Estados Unidos da América do Norte}

Pode-se dizer, seguramente, que o bem de família nasceu, com tratamento jurídico específico, na República do Texas, sendo certo que, no Direito americano, desponta ele como sendo uma pequena propriedade agrícola, residencial, da família, consagrada à proteção desta.

O jurista americano Rufus Waples 3 conceitua o homestead como " $a$ residência de família, possuída, ocupada, consagrada, limitada, impenhorável e, por diversas formas, inalienável, conforme o estatuído na lei”.

Como se sabe, assim, o homestead surgiu no Texas, antes de sua incorporação aos EUA, que se deu no ano de 1845, regulamentado pela lei de 26.1.1839 (Homestead exemption act).

É necessário que se sintam os antecedentes históricos que motivaram o surgimento dessa lei, mesmo que sucintamente, para que se tenha melhor noção do instituto sob cogitação. Saídos do jugo da Inglaterra, os Estados Unidos eram um território

3 LEHR, Ernest. Étuds sur le droit civil des États-unis de l'Amérique du Nord. Paris: Sirey, 1906. p. 74. 
pobre, uma vasta área de terra no aguardo de uma civilização. Dada a fértil condição do solo americano, desenvolveu-se a agricultura e o comércio de forma vertiginosa, pelo árduo trabalho desse povo. Em face desse grande desenvolvimento, os bancos da Europa fixaram-se naquela promissora região, possibilitando operações bancárias, reunindo os pequenos capitais americanos, prestando inestimáveis serviços à economia americana, com o desenvolvimento cada vez maior da agricultura, do comércio e da indústria. Por volta de 1830, com a especulação sem peias, com desmesurados pedidos de empréstimos de grandes capitais e com descontrole de emissão de dinheiro, este não mais representava o lastro-ouro, o capital efetivo das casas de crédito.

Tudo porque, ao lado dos grandes benefícios criados pelos empréstimos, como escolas, hospitais, canais, estradas, fábricas etc., criou-se a ilusão dourada do lucro fácil que levou o povo a ultrapassar os limites da realidade, abusando desses empréstimos e do elevadíssimo nível de vida no prisma econômico-financeiro. Viria, como conseqüência, a grande crise entre os anos de 1837 a 1839, iniciando-se, dentre outros fatores, com a falência de um banco de grande expressão de Nova York, em 10.5.1837, que foi o estopim do desencadeamento de uma verdadeira explosão no campo econômico e financeiro que viria a conturbar toda a civilização americana e para gravar em seus anais o retrato de uma de suas mais adversas épocas.

A seu turno, Paul Bureau ${ }^{4}$ figura esse sombrio panorama, elucidando que, então, os papéis bancários deixaram de circular ao par e perderam de dez a vinte, e mesmo oitenta por cento, de seu valor, conforme a solvabilidade do estabelecimento emissor, tendo o câmbio chegado a vinte e dois por cento sobre o da França e o da Inglaterra; os metais desapareceram de circulação e os preços de todas as mercadorias, sobretudo do algodão, aviltaram-se. Para fazer-se uma idéia da extensão do desastre: 959 bancos fecharam suas portas, somente no ano de 1839, e, durante a crise, entre os anos de 1837 a 1839, ocorreram 33 mil falências e uma perda de 440 milhões de dólares, ou seja, perto de dois bilhões e trezentos milhões de francos, à época.

Os credores realizaram penhoras em massa nos bens dos devedores, nesse amargo momento, em que era nula qualquer pretensão à obtenção de crédito, tendo estes que sofrer essa execução por preços irrisórios, resumindo-se um patrimônio, composto de terra, animais e instrumentos agrícolas, em quase nada, ante o exorbitante valor por eles pago antes da crise.

4 BUREAU, Paul. Le homestead ou l'insaisissabilité de la petite propriété foncière. Paris: Arthur Rousseau, 1895. p. 45. 
As quebras contínuas e inumeráveis foram inevitáveis e atingiram profundamente a família americana, de uma hora para a outra, em completo desabrigo econômico e financeiro.

Foram, nessa época, após veemente movimento democrático dos trabalhadores em geral, editadas inúmeras leis protegendo-os, surgindo, em 1833, a que aboliu a prisão por dívidas, princípio hoje consagrado nas Constituições dos povos civilizados.

Esclarecem os Autores, ante a História, que, logo após a separação do Texas do território mexicano, constituindo-se em República independente, recebeu grande massa de emigrantes americanos que procuravam reconstruir seus lares ou iniciar nova vida, nesse promissor território, com ótimas terras e bom clima, ante a proteção, vantagens e grandes garantias que eram oferecidas pelo Governo texano.

Essa emigração, que existiu em grande número, ainda quando o Texas fazia parte do México, e que preocupou este Governo, continuou sem cessar, num crescendo, de tal forma que a população do Texas era quase que totalmente composta de americanos.

As estatísticas comprovam que, em 1836, a população texana não ultrapassava de 70 mil habitantes e que, em 1840, ela foi a 250 mil.

A Constituição texana, de 1836, delineara, antes da lei do homestead, as linhas gerais do instituto, possibilitando a todo cidadão do Texas, com exceção dos negros africanos e de seus descendentes, a obtenção, junto ao Governo, de uma pequena porção de terras do Estado, desde que fosse chefe de família, e porção menor, se celibatário.

Só em 1839, em 26 de janeiro, como visto, foi promulgada a Lei do Homestead, neste teor: "De e após a passagem desta lei, será reservado a todo cidadão ou chefe de uma família, nesta República, livre e independente do poder de um mandado de fieri facias ou outra execução, emitido por qualquer Corte de jurisdição competente, 50 acres de terra, ou um terreno na cidade, incluindo o bem de família dele ou dela, e melhorias que não excedam a 500 dólares, em valor, todo mobiliário e utensílios domésticos, provendo para que não excedam o valor de 200 dólares, todos os instrumentos (utensílios, ferramentas) de lavoura (providenciando para que não excedam a 50 dólares), todas ferramentas, aparatos e livros pertencentes ao comércio ou profissão de qualquer cidadão, cinco vacas de leite, uma junta de bois para o trabalho ou um cavalo, vinte porcos e provisões para um ano; e todas as leis ou partes delas que contradigam ou se oponham aos preceitos deste ato são ineficazes perante ele. Que seja providenciado que 
a edição deste ato não interfira com os contratos entre as partes, feitos até agora (Digest of the Laws of Texas $\S 3.798)$ ". 5

Teve esse diploma legislativo, principalmente, em vista fixar o homem à terra, objetivando o desenvolvimento de uma civilização, cujos cidadãos tivessem o mínimo necessário a uma vida decente e humana.

A Lei do Homestead trouxe ao lado da impenhorabilidade dos bens domésticos móveis, que foram, primeiramente, objeto de proteção, também a dos bens imóveis. Daí residir, nesta última característica, a originalidade do instituto e o objeto central de sua abrangência.

Esse homestead estadual, após seu nascimento, em 1839, no Texas, é verdade, espalhou-se pelo território americano, implantando-se, no ano de 1849, em Vermont e Wisconsin; no de 1850, em Nova York e Michigan; no de 1851, em Indiana, Nova Jersey e Delaware e, no de 1864, em Nevada. Nestes Estados do Norte, mais necessitados do instituto, veio ele como remédio imediato, que, em seguida, foi sendo adotado no Sul, dados os nefastos efeitos da Guerra de Secessão causados àquele rico território, primeiramente, no ano de 1865, na Flórida e Virgínia, depois, no de 1868, em Arkansas e Alabama; no de 1870, no Mississipi e na Geórgia. ${ }^{6}$

As bases do bem de família, traçadas na primitiva República do Texas, permanecem vivas na legislação americana atual, nos Estados que admitem sua existência.

Assim, ainda legislam sobre o homestead os seguintes Estados norteamericanos: Alabama, Alaska, Arizona, Arkansas, Califórnia, Colorado, Connecticut, Flórida, Havaí, Idaho, Illinois, Iowa, Kansas, Kentucky, Louisiana, Maine, Massachusetts, Michigan, Minnesota, Mississipi, Missouri, Montana, Nebraska, Nevada, New Hampshire, Novo México, Nova York, Carolina do Norte, Dakota do Norte, Ohio, Oklahoma, Oregon, Carolina do Sul, Dakota do Sul, Tennessee, Texas, Utah, Vermont, Virgínia, Washington, Virgínia Ocidental, Wisconsin e Wyoming, não existindo legislação a respeito, entretanto, nos Estados de Delaware, Geórgia, Indiana, Maryland, Nova Jersey, Pennsylvânia e Rhode Island. ${ }^{7}$

\footnotetext{
5 BUREAU, Paul. Le homestead ou l'insaisissabilité de la petite propriété foncière. Paris: Arthur Rousseau, 1895. p. 63-64.

${ }^{6}$ Id. Ibid., p. 69-70.

7 Law Digest, Martindale-Hubel - Law Directory, Summit, New Jersey, 1972, v, p. respectivamente pela citação dos Estados, 34/35; 76; 110; 149; 201; 257/258; 305; 436/437; 541; 582/583; 640; 741/742; 780; 836; $890 / 891 ; 936 ; 1.039 ; 1.014 / 1.105 ; 1.156 ; 1.200 ; 1.252 ; 1.295 ; 1.340 ; 1.391 ; 1.437 ; 1.555 ; 1.619 ; 1.692 ; 1.743$; $1.797 ; 1.851 / 1.852 ; 1.897 ; 2.080 ; 2.128 ; 2.175 ; 2.225 ; 2.272 ; 2.305 ; 2.339 / 2.340 ; 2.407 / 2.408 ; 2.453 ; 2.501$;
} 
Dos cinqüenta Estados americanos, os que tratam da matéria fazem-no da forma mais variada. Realmente, em cada Estado uma peculiaridade, quer quanto às pessoas que podem constituir o homestead, quanto à maneira dessa constituição, quanto à limitação de área ou de valor, sendo certo, entretanto, que os elementos essenciais do instituto permanecem inatacados.

\section{Expansão do bem de família a outros países}

Situarei, neste ponto, o instituto do bem de família, revestindo as feições do modelo texano, em vários países.

No Canadá, implantou-se o bem de família com a lei federal de 1878; na Suíça, o asilo ou abrigo de família, instituiu-se, como no Brasil, pela vontade unilateral do proprietário do imóvel (art. 350 do Código Civil); na França, editou-se a lei sobre o bien de famille, de 12 de julho de 1909; na Itália, o instituto do patrimonio familiare, hoje fondo patrimoniale, vem regulado pelo Código Civil, de 1942 (arts. 167 a 171); em Portugal, existe o casal de família, instituído pelo Decreto n. 7.033, de 16 de outubro de 1920; no México, o patrimônio da família é regulado pelo Código Civil, de 1928, que teve início de vigência em 1932; na Venezuela, el hogar regulou-se, primeiramente, no Código Civil, de 1904, depois no de 1916, após, no de 1942; na Argentina, o bien de familia instituiu-se pela Lei n. 14.394, de 14 de dezembro de 1954.

Deixei patente em minha tese que o insucesso do bem de família, nos países que o adotaram, deveu-se, principalmente, a uma tentativa de defender a família somente pelo bem imóvel, mas com excesso de formalismos em sua instituição, como escritura pública, registro imobiliário e publicação de editais, tornando o bem, não-só impenhorável, mas inalienável, com dificuldades na sua extinção, quando em caso de necessidade de venda do bem, ante a existência de filhos menores, ficando a família, às vezes, em circunstâncias de risco, vivendo em belo imóvel, sem recursos para sua subsistência. A fixação do valor do bem de família é também um entrave na sua instituição, com dificuldades na sua avaliação e na sua atualização em face da inflação. Na Venezuela, ${ }^{8}$ por exemplo, exige-se

2.549/2.550 (com legislação); 361; 490; 497; 977; 1.502; 1.946; 2.031 (sem legislação). Conforme pesquisa realizada em 1972.

8 AZEVEDO, Álvaro Villaça. Bem de Família, com comentários à Lei n. 8.009/90. 4. ed. rev. e ampl. São Paulo: Revista dos Tribunais, 1999. p. 76. Pela Lei francesa (de 1909), as ressalvas de direitos de credores necessitam de julgamento e de homologação judicial e de registro (artigos $7^{\circ}$ a $9^{\circ}$ ). op. cit., p. 60 . 
até a intervenção do juiz, como também em Portugal $^{9}$ e no México, ${ }^{10}$ para sua instituição ou extinção.

\section{Possibilidade de unificação legislativa internacional do bem de família' ${ }^{11}$}

Pela pesquisa que fiz de Direito Comparado, o instituto bem de família, com caráter mais social do que jurídico, não andou, até o presente, bem regulamentado nas leis dos povos que o adotaram.

A sua inutilidade, quase que completa, decorre da infelicidade de seu tratamento jurídico-social, como já evidenciado.

O grupo vivente familial clama por uma programática protetiva mais simples, no sentido, pelo menos, da preservação da sua sobrevivência.

É certo que cada povo apresenta uma peculiaridade sociológica, política, econômica e jurídica, entretanto, há certos pontos fundamentais que se identificam.

Quanto ao instituto em causa, as legislações todas insistem em arraizá-lo, como se o imóvel, tornando-se inalienável, ou com providências excessivas e formalismos, fosse sua única forma de defesa contra os reveses da existência. Não deixa de ser demagógica a idéia, pois poucas são as famílias detentoras de patrimônio imobiliário.

Daí a possibilidade de uma legislação uniforme, no plano internacional, com fundamento na impenhorabilidade do imóvel e dos móveis que o guarnecem, pela simples fixação, nesse imóvel, da residência de seu proprietário ou de seu possuidor, com sua família, ou ainda de seu locatário ou comodatário, com a conseqüente impenhorabilidade dos móveis no imóvel existentes.

\section{Conceito do novo bem de família}

O bem de família, como estruturado na Lei brasileira, n. 8.009, de 1990, é o imóvel residencial, urbano ou rural, próprio do casal ou da entidade familiar, e/ou móveis da residência, impenhoráveis por determinação legal, não por iniciativa do proprietário ou do possuidor.

Como resta evidente, nesse conceito, o instituidor é o próprio Estado, que impõe o bem de família, por norma de ordem pública, em defesa da célula familial.

\footnotetext{
9 AZEVEDO, Álvaro Villaça. Bem de Família, com comentários à Lei n. 8.009/90. 4. ed. rev. e ampl. São Paulo: Revista dos Tribunais, 1999. p. 72 (artigos $24^{\circ}$ e $30^{\circ}$ do Decreto n. 7.033, de 1920).

${ }^{10}$ Id. Ibid., p. 73 (arts. 731 e 742 do Código Civil mexicano).

11 Id. Ibid., p. 84-86.
} 
Nessa lei emergencial, não fica a família à mercê de proteção, por seus integrantes, mas é defendida pelo próprio Estado, de que é fundamento.

O objeto do bem de família é o imóvel, urbano ou rural, destinado à moradia da família, não importando a forma de constituição desta, bem como os móveis, que guarnecem a residência do seu proprietário ou possuidor.

A criação desse bem de família independe de qualquer formalidade: basta residir em imóvel próprio, para que este seja bem de família como os bens móveis que o guarnecem, ou residir em imóvel alheio, para que os mesmos bens móveis também sejam de família.

Em qualquer dessas circunstâncias, estaremos em face do bem de família, sempre impenhorável, enquanto durar a residência. Com a mudança da residência, cessa a impenhorabilidade do bem de família anterior, criando-se nova impenhorabilidade quanto aos bens sujeitos à nova residência.

\section{Requisitos do novo bem de família}

Podemos enumerar os requisitos indispensáveis à existência do novo bem de família, constantes da mencionada Lei brasileira:

a) O objeto da impenhorabilidade é, principalmente, imóvel residencial próprio do casal ou da entidade familiar; bem como os móveis que guarnecem a residência do casal, seja o imóvel próprio ou simplesmente ocupado.

b) Além da propriedade do imóvel ou de sua posse, é necessário que os membros da família nele residam.

Esse requisito de manter residência no imóvel é tão-importante que basta que nele resida o pai ou seus filhos, para ser a impenhorabilidade automática, mesmo que não exista registro desse mesmo imóvel, na Circunscrição Imobiliária.

\section{Exceção de impenhorabilidade e a interpretação jurisprudencial}

A Lei brasileira exclui da impenhorabilidade os veículos de transporte, as obras de arte e os adornos suntuosos.

Por essa mesma lei, os bens do devedor, sem os benefícios do bem de família, podem ser penhorados em razão de: a) crédito de trabalhadores (empregados domésticos e trabalhadores, em geral, que prestam serviços na residência, instituída em bem de família); b) crédito para construção ou aquisição do imóvel; c) crédito de alimentos; d) créditos tributários, contribuições e obrigações propter rem (é passível de execução, assim, o 
bem de família, em razão de débitos derivados de impostos, predial ou territorial, taxas e contribuições, sobre esse imóvel incidentes, bem como despesas geradas por esse imóvel, tais as de condomínio e as de construção de muro divisório); e) crédito hipotecário (quando o imóvel é oferecido em garantia); f) aquisição criminosa (do bem de família); g) crédito de fiança locatícia (quando o proprietário do bem é fiador, em contrato de locação, dando o imóvel em garantia, criando-se, com isso, verdadeiro direito real).

\section{Espécies de bem de família que devem existir}

A Autor já alertava, em 1972, que a espécie de bem de família tratada no Código Civil brasileiro, como nos Códigos Civis de legislações estrangeiras, fundada na instituição de uma coisa imóvel (modelo texano), com excesso de formalismos e com a inalienabilidade do bem, não tem, por si, qualquer subsistência, pois não resolve o sério problema, qual seja, o de descoberta de instituto, capaz de pôr a salvo o patrimônio familiar. Essa espécie de bem imóvel de família assenta suas bases na determinação, atualmente, dos cônjuges e dos que vivem em entidade familiar.

Propus, então, primeiramente, a criação de duas novas espécies de bem de família: uma voluntária móvel, a par da já existente (imóvel), e outra involuntária ou legal móvel e imóvel.

Em razão dessas novas espécies de bem de família, posso, agora, classificálo em duas grandes categorias: a) voluntário, decorrente da vontade dos interessados, com instituição, nesse regime, de bem móvel ou imóvel; e b) involuntário ou legal, que, por não depender da manifestação da vontade do instituidor resulta de estipulação legal, por norma de ordem pública, objetivando bem móvel ou imóvel.

Podemos, assim, visualizar essa classificação no quadro adiante:

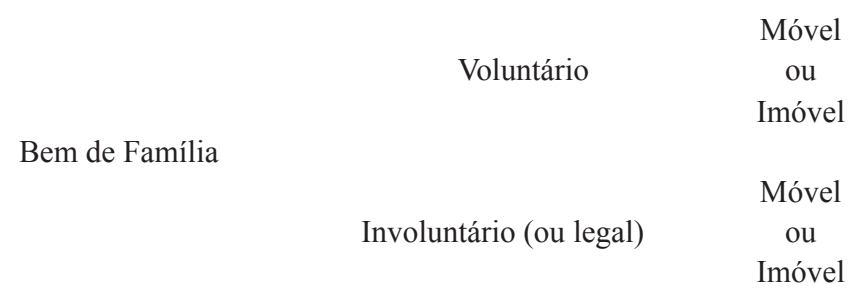

Como podemos observar, o bem de família voluntário, móvel ou imóvel, nasce pela vontade do instituidor, pela própria vontade individual, nos moldes preestabelecidos na lei; o bem de família involuntário ou legal, que deve ser objeto da 
unificação legislativa internacional, institui-se por determinação da lei, pela vontade soberana do Estado, garantidora de um mínimo necessário à sobrevivência da família.

É preciso evidenciar que o bem de família é o patrimônio, a propriedade, num sentido protetivo do núcleo familiar, devendo, por isso, apresentar-se com maiores limitações, além das normais.

9. Minha proposta de lei sobre o bem de família internacional, ao modelo da Lei brasileira

Impenhorabilidade do bem de família

Art. $1 .^{\circ}$ - O imóvel residencial próprio do casal, ou da entidade familiar, é impenhorável e não responderá por dívida de qualquer natureza, contraída pelos cônjuges pelos companheiros ou pelos pais ou filhos que sejam seus proprietários e nele residam, salvo nas hipóteses previstas nesta Lei.

Parágrafo único. A impenhorabilidade compreende o imóvel sobre o qual se assentam a construção, as plantações, as benfeitorias e acessões de qualquer natureza e todos os equipamentos, inclusive os de uso profissional, e móveis que guarnecem a residência.

Art. $2^{\circ}$ - No caso de imóvel locado ou dado em comodato, a impenhorabilidade aplica-se aos bens móveis que guarnecem a residência e que sejam de propriedade do locatário ou do comodatário.

Art. 3. ${ }^{\circ}$ - Em qualquer das situações dos artigos anteriores, excluem-se da impenhorabilidade os veículos de transporte, as obras de arte e os adornos suntuosos.

Art. $4^{\circ}$ - A impenhorabilidade é oponível em qualquer processo de execução de qualquer natureza, salvo se movido:

I - em razão dos créditos de trabalhadores da própria residência e das respectivas contribuições previdenciárias;

II - pelo titular do crédito decorrente do financiamento destinado à construção, à reforma ou à aquisição do imóvel, no limite dos créditos e acréscimos constituídos em função do respectivo contrato;

III - pelo credor de pensão alimentícia;

IV - para cobrança de impostos, predial ou territorial, taxas e contribuições, e despesas condominiais, sempre devidas em função do imóvel familiar;

V - para execução de hipoteca sobre o imóvel oferecido como garantia real pelo casal ou pela entidade familiar; 
VI - por ter sido adquirido com produto de crime ou para execução de sentença penal condenatória a ressarcimento, indenização ou perdimento de bens;

VII - por obrigação decorrente de fiança concedida em contrato de locação.

Art. 5. ${ }^{\circ}$ - Não se beneficiará do disposto nesta Lei aquele que, sabendo-se insolvente, adquire de má-fé imóvel mais valioso para transferir a residência familiar, desfazendo-se ou-não da moradia antiga.

Parágrafo único. Neste caso poderá o juiz, na respectiva ação do credor, transferir a impenhorabilidade para a moradia familiar mais valiosa para execução ou concurso, conforme a hipótese.

Art. 6. ${ }^{\circ}$ - Quando a residência familiar constituir-se em imóvel rural, a impenhorabilidade restringir-se-á à sede de moradia, com os respectivos bens móveis, e à área limitada como pequena propriedade rural, nos moldes da lei.

Art. $7^{\circ}$ - Para os efeitos de impenhorabilidade, de que trata esta Lei, considera-se residência um único imóvel utilizado pelo casal ou pela entidade familiar, para moradia permanente.

Parágrafo único. Na hipótese de o casal, ou entidade familiar, ser possuidor de vários imóveis utilizados como residência, a impenhorabilidade recairá sobre o de menor valor, salvo se outro tiver sido registrado, para esse fim, no Registro de Imóveis e na forma do bem de família voluntário, nos moldes da lei.

Art. $8 .^{\circ}$ - Esta Lei entrará em vigência na data de sua publicação.

Art. 9. ${ }^{\circ}$ - Revogam-se as disposições em contrário.

São Paulo, março de 2007. 